\title{
The Touring Science Centre- an example of collaboration between a museum and a school
}

\section{Eva Insulander and Elisabeth Öhman}

\section{Museum and school partnerships}

The semi-formal environment of the museum has as its mission, among other things, to collect, preserve, and exhibit the heritage of humanity for the purposes of education and enjoyment. The formal environment of the school, on the other hand, has as its purpose to create the best conditions for children's development and learning and to help improve pupils'learning outcomes. When Sweden moved from a rule-governed system to a goal-governed system, ${ }^{1}$ information about the quality of schools became essential. Schools - and teachers - are now held accountable for providing a good education for all. In line with this reform, learning outcomes and assessments have become of increasing importance at national, regional, and individual levels. The differences between the two institutions (school and museum) often result in different strategies and agendas regarding field trips and programs. Museums in general are set up to develop broader knowledge and understanding. However, as they also focus on attracting schools, in many cases they try to provide for the curriculum and make sure that a field trip will support the curriculum standards. As teachers search for museum programs, they want to know that their pupils will be able to meet specific learning objectives.

Previous studies on relations between museums and schools have shown difficulties regarding power relations; often, museum educators have a dominant role during visits while the school teachers have an ill-defined educational role (Mathewson \& McKeon, 2002). There are differences in how each group sees the purposes of a visit. Whereas museum educators consider a successful visit to be one where the pupils find personal relevance in the exhibition and feel comfortable, teachers, on the other hand, focus on the relevance of the visit in relation to the curriculum and the practical schoolwork. It is not unusual for museum educators to be critical of teachers' lack of involvement and lack of knowledge in relation to the subject area represented in the museum (Griffin, 2007). Allen (2004) claimed that science museums can be difficult learning environments simply because they offer a myriad of choices and lack the clear goals of a curriculum. Teachers are not usually aware of how to gain maximum benefit from science centres (Cox-Petersen et al., 2003). 
Genuine collaboration between the school and the museum seems rare. Cigdemoglu and Köseoğlu (2019) see the need for professional development models that can integrate informal and formal learning framings. Professional development programs provided by science centres and museums are often offered to schools, but they take place at the museum and rarely offer support or coaching at the participating schools' sites (Phillips et al., 2007). In order for the partnership to succeed, Griffin (2007) claims that museum educators and school teachers need a better understanding of each other's pedagogical contexts and strategies.

The Designs for Learning (DFL) framework emphasizes, among other things, the importance of understanding how institutional norms and power relations frame learning. This chapter explores some of the challenges and opportunities for teaching and learning in the collaboration between a science and technology museum (a semi-formal framing) and an elementary school-a formal framing; also see Chapters 1 (Selander), 7 (Insulander, Lindstrand \& Selander) and 9 (Insulander \& Svärdemo-Åberg), in this volume. We will show how differences between these two institutional framings have consequences for both teachers and museum educators as they meet in collaboration. This study is a critical reflection on the possible strengths and weaknesses, with the intention of using the findings as a basis for the development of improved relations and understandings between the two groups.

\section{A partnership focussing on digital resources}

In Sweden, the government recently decided to strengthen the national curriculum regarding digital skills (Swedish National Agency for Education, 2011), and computer programming and computational thinking are now being introduced in both formal and informal learning environments. However, many teachers lack any knowledge about programming, and a majority of the teachers are not familiar with basic programming concepts (Nouri et al., 2020). As science museums wish to increase school students' interest in science and technology, and to develop their competence in programming, there is an incentive for collaboration with the schools that really need support. Previous research has shown that science museums, through their exhibits, resources, and established maker spaces, can introduce a contextualized use of computational thinking that complements the work of the formal school framing (Bowler \& Champagne, 2016; Mesiti et al., 2019; Moore et al., 2020). Kjällander et al. (2016) point out that programming can be approached by using physical materials, such as robots and various applications, where pupils can use visual programming.

The initiative to engage in the development of new competencies came from a Swedish science and technology museum, as a response to the Swedish national curriculum regarding digital competences and programming. Observations of activities and interviews with museum educators and school teachers 
provided information about the teaching and learning interactions and cooperative practices at both sites. The purpose of the study was to illuminate and to discuss how the site-specific resources and practices of the museum's semiformal framing contributed to the school's formal goal-oriented work. Our questions were:

1 How is programming designed?

2 How is programming represented and transformed in the program across the framings of school and museum?

3 What do museum educators and teachers recognize as significant when working with programming?

Using a design-theoretic perspective allowed us to investigate how the institutional frames influence both teaching and learning. This research has also allowed us to demonstrate how museums may contribute to the curricular aims of the school by offering solutions and a place and space that expands the idea of where learning takes place.

\section{Context of the study and research design}

The "Touring Science Centre-programming in school" was a non-profit educational program for middle schools (for students aged 10 to 12 years) located in socially vulnerable areas of Sweden. It was produced by a Swedish science and technology museum involving a mobile platform that focussed on programming and aiming to motivate the interest of children and young people in technology and science through creative processes and collaborative problemsolving. In total, three museum educators were responsible for carrying out activities at different schools. They arrived at the schools in a van filled with resources for programming activities: digital tablets with coding software, and LEGO robots.

The school and the four different classes chosen for this particular study were selected due to their availability and the fact that they had already scheduled bookings. The data were collected during two months of field work, and consisted of observations from the activities included in the educational program, which included: (a) one introductory workshop with teachers at the school, (b) $4 \times 1$ workshops with pupils at the school, (c) $4 \times 1$ workshops with pupils at the museum, and (d) one follow-up workshop with teachers at the school (see Table 8.1). Our data included field notes, photographs of work processes (without identifying data), documentation of educational material, and interviews with the teachers and museum educators. All teachers gave informed consent to observation, and four teachers agreed to share their thoughts about the educational program in interviews.

The three museum educators involved in the program also attended an interview. These interviews were semi-structured and followed three themes: 
programming, schools in vulnerable areas, and the collaboration between the school and the museum. The interviews were transcribed and a thematic content analysis involving a reflexive movement between data collection and analysis was conducted. We focussed on the analytical concepts of framing, design, and transformation as a filter, through which the material was interpreted. The museum educators were once again informed about the purpose and aim of the study, and were given the opportunity to ask questions about the study and to cease their participation without having to give any specific reason. An informed consent form was signed by the participants. The schools' and the participants' names were anonymized. In Table 8.1, the documented activities are summarised.

\section{Analytical approach}

The thematic content analysis of the teaching and learning in a cooperative practice was carried out using some of the central concepts from the Designs for Learning framework, described in Chapter 1 by Selander of this book. In the context of this study, framing operates on two levels. It refers both to the institutional and organizational principles of the school vs. the museum, and to the individual framing and interpretation of a representation, based on individual preferences, cultural values, and so on (see also Lindstrand on affordances, Chapter 3, this volume). Different, institutionally based expectations of how communication and learning will occur in a museum or in a school can be observed through, for example, focussing on learning outcomes in school vs. enjoyment in the museum.

Table 8.I Documented activities within the educational program. (Table constructed by the authors)

\begin{tabular}{lll}
\hline Framing & Participants & Activities \\
\hline At the school &
\end{tabular}

\section{At the school}

School workshop A

School workshop I

School workshop I

School workshop I

School workshop I

\section{At the museum}

Museum workshop 2 Fourth grade pupils, group A

Museum workshop 2 Fourth grade pupils, group B

Museum workshop 2 Fifth grade pupils, group $A$

Museum workshop 2 Fifth grade pupils, group B

\section{At the school}

School workshop B All teachers at the school
Introduction to programming Introductory programming Introductory programming Introductory programming Introductory programming

Robot programming

Robot programming

Robot programming

Robot programming 
The framing also affects the design — an exhibit or a workshop at the museum will be designed differently from a textbook or a lesson in school, depending on different expectations and purposes. Here, Designs for Learning refers to the educational program at the museum, which differs from the tasks that are given in schools. Design in our study (about programming) refers to the form as an integral part of the content in a social practice (Kress \& Selander, 2012). It also indicates designs in learning for both teachers and pupils in the series of workshops that involved hands-on practice with programming activities at the two different sites.

The pupils participated in one workshop at the school and one at the museum. We studied how programming, as curriculum content, is represented and transformed across the institutional framings of the school and the museum.

\section{Findings}

\section{Programming as edutainment vs. education?}

The program was designed by the museum with the intention of motivating, through creative processes, children and young people to be interested in technology and science. It involved workshops taught by two museum educators who (after an introductory workshop with the teachers) showed how one could carry out simple programming and collaborative problem-solving with the pupils at the school. It involved simple block programming, a visual and in many ways intuitive puzzle, that the pupils understood fairly quickly. The block programming was done with LEGO robots from LEGO Education and micro:bit coding. The MakeCode editor is a visual, intuitive programming environment with pre-programmed puzzle pieces that can be combined in different sections to create instructions for controlling, for example, a pedometer or a robot.

Eight LEGO robots were placed on the table in the front of the classroom, and the enthusiastic and expectant pupils rushed into their first programming workshop with the museum educators. After a short introduction, it was time for the first task. The pupils were divided into small groups with an iPad, a LEGO robot, and a wax cloth, with an obstacle course for each group. The challenge for the pupils was to program a robot to go through the obstacle path on the wax cloth, steer past various hindrances, and eventually reach the end (Figure 8.1). The workshop was designed for collaborative problem-solving activities, for example, how to manage the robot through the obstacle path. In the workshop, programming was represented by way of the technically modified toys-in this case, the robot and the colourful small symbols in the micro:bit coding. In the first workshop, programming was represented as a playful game.

In the second workshop, at the museum, the coding of the robot's movements was transformed in a new and different way. The pupils, in groups of three, were asked to build an alarm system. Their coding would give the robot a new 


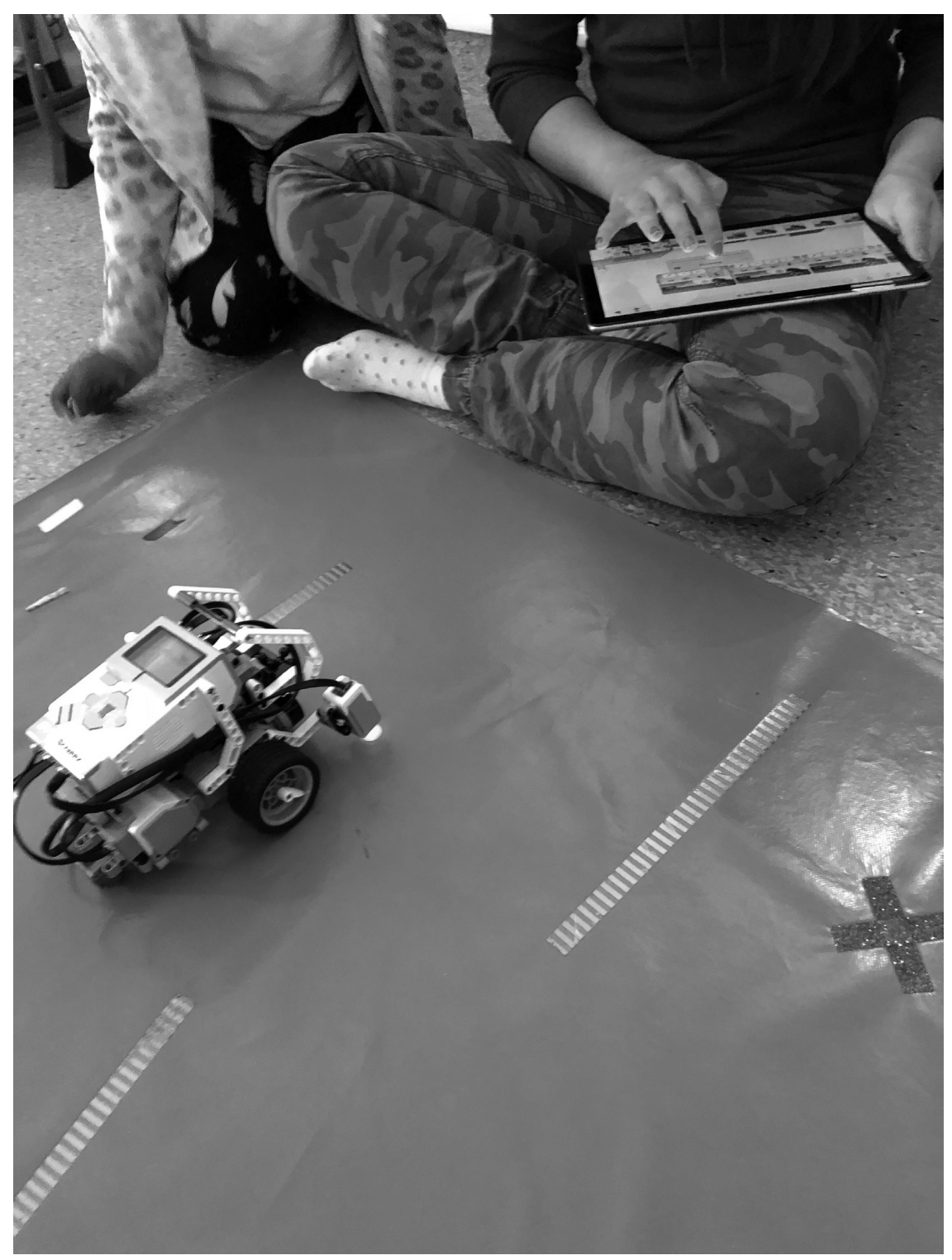

Figure 8.I A LEGO robot on the wax cloth.

Source: (Photographed by Lisa Öhman, ownership by chapter authors)

movement by attaching a bell or other object to one of the robot's parts (Figure 8.2). This was a more difficult task than the previous one; it was not as intuitive and demanded more creative solutions and logical thinking. However, most groups succeeded in solving this problem as well. Finally, they got to present their 


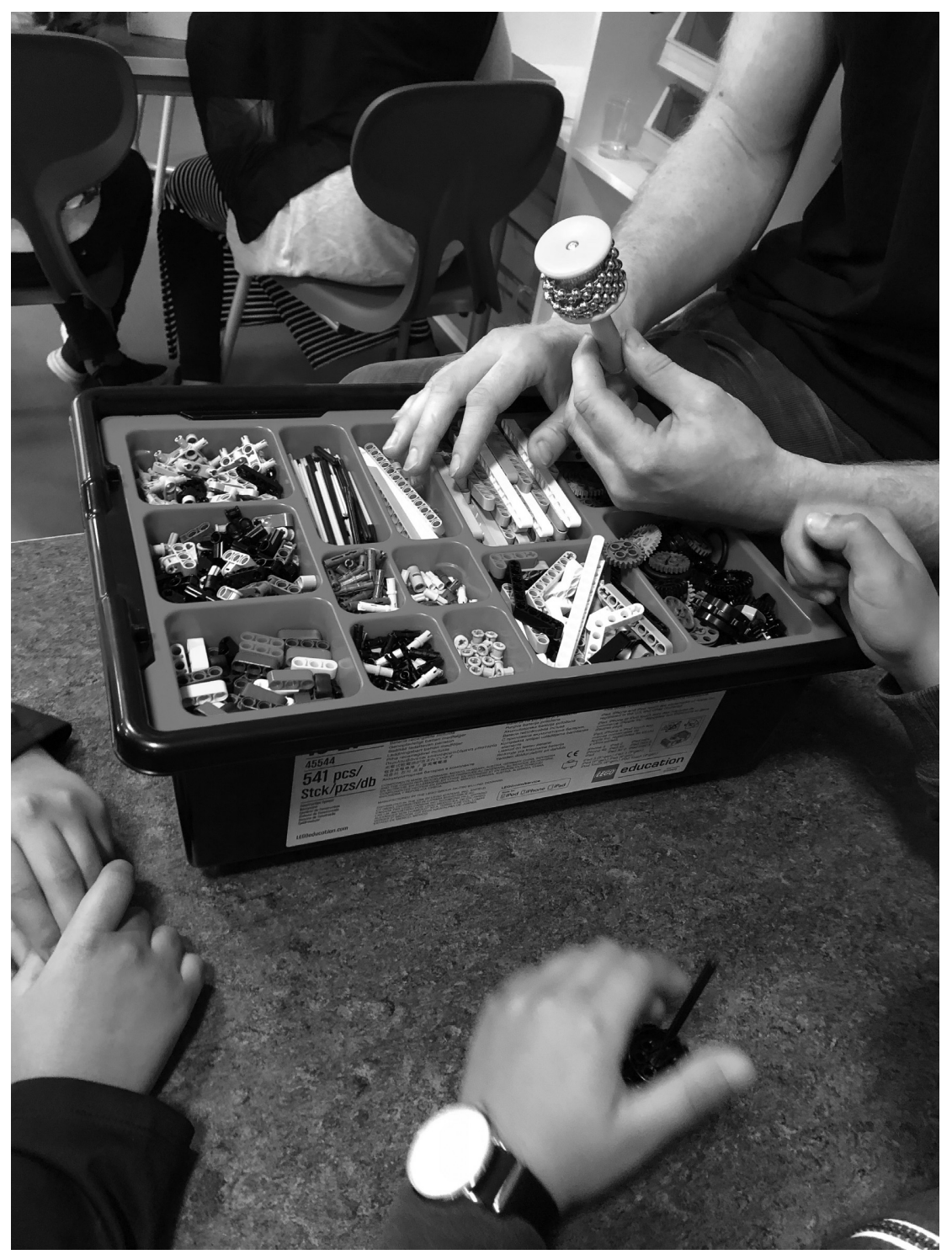

Figure 8.2 The rattle to be attached to the LEGO robot.

Source: (Photographed by Lisa Öhman, ownership by chapter authors)

solutions to one another. In this second workshop, programming was represented in terms of problem-solving.

As stated in their interviews, the educators at the museum wanted to support young people's interest in programming and, following the museum's mission 
statement, contribute to a wider recruitment to technical education. They also wanted to offer resources in order to attract new types of visitors to the museum. Yet another aim was to empower teachers, and to provide them with tools to stimulate young people's interest in programming. What came to be recognized as an important side-effect of the program was that the museum educators found the communication with the school meaningful. This is worth mentioning, because, as mentioned above, it is not unusual for museum educators to be critical of the teachers' lack of involvement and lack of competency (Griffin, 2007).

In this specific project, as noted above, the school and the museum had joint interests in programming, although from two different points of view. The teachers at the school had twofold objectives when participating in the program: to support the pupils' knowledge in programming, and to create a plan for further progression concerning their own digital competence. The museum educators' interest was not primarily in learning, but in offering meaningful and fun activities to support the pupils' interest. This also could be noticed in their choice of, for example, material and collaborative activities.

ME1: After all, we cannot teach them to crack a code. We may not have the goal that they should be able to go home and hack into their neighbours' network or something, it is rather that they should go home with a sense of-wow-this is fun, I want to continue with this.

(Museum educator)

In contrast to the museum's goals of creative work and of having fun, the school teachers pointed out that the project was not just a fun event. Instead, they talked about the need for increased skills and improved learning outcomes. They wished for their pupils to understand what programming could be in the school context, and to understand its importance for professional life and for the future. In other words, they wanted the pupils to be empowered (see Findings below). Further, the teachers wanted to transform programming so it could fit into their curriculum goals, according to the institutional framing of the school.

\section{Power relations and institutional clashes}

The institutional framing of the school involves an emphasis on programming as part of the curriculum. Representing the program as something serious, and not only a fun event, became a way for the teachers to legitimize the meaning and the value of programming at the school. However, one of the responsible teachers in the school's digital competence group revealed that, at different schools, teachers did not agree on what programming is, or how it could be taught. There were, for example, disagreements concerning the assessment of the learning outcomes. The mathematics teachers seemed unwilling to include programming in their teaching, arguing that it was not included in the syllabus. 
Other teachers tended to be more interested in using both digital and analogue tools to explore programming in the teaching of their subjects.

T4: There are two different factions in the school right now. Like many other schools we have a local educational plan just to secure the knowledge of programming because we have been given an assignment to get it into different school subjects. But then we have different factions where the math teachers say it is not in the knowledge requirements in the syllabusso we do not need to work with robots or Scratch program block programming ... in the way they do it in algebra, where there are some exercises similar to block programming, you work with binary numbers and they are also included in the programming.

Teachers are facing new challenges when it comes to understanding the role of digital competence in the organization of schoolwork. The school we visited had not yet decided on a strategy for how to approach programming, but intended to devise a local plan after the collaboration with the museum ended. The expectation was that the museum's program would provide knowledge for teachers as well as for pupils, and that the collaboration would be a helpful first step in the school's work to produce their own strategy for teaching programming. Previous studies have pointed out the difficulties regarding the power relations between schools and museums (e.g., Mathewson \& McKeon, 2002). However, this is not the case in our example, since the collaboration seemed to be equally fruitful for both parties, and the development of programming in the school appeared to cause changes in teaching and learning practices.

\section{Importance of materiality and place}

According to the teachers, hands-on materials make it easier for children to reach the goals of digital competence. The museum does not only show and tell, but also encourages children to do and experience programming. The design of the workshops - with hands-on material and the guidance of the museum educators - also made it easier for the teachers to understand what programming might entail. A fruitful approach, according to the museum educators, seems to be "to talk less but do more" and to let both teachers and pupils discover and work by themselves.

The teachers underlined that the workshops needed to be clearly planned: The pupils needed to know what was expected and to get an idea of what was going to happen. Otherwise there could have been a loss of focus and interest. For the pupils, not only was planning central, but also being able to work with multiple modes of expression including hands-on materials. The museum educators used a projector to show how the activity would be performed step by step and how the robots worked, which was helpful to many pupils with Swedish as a second language. The teachers concluded that the visual aids and the 
concrete materials supported learning. The museum educators also highlighted the museum as an opportunity for, and an alternative to, school learning, as something that could attract curiosity and a desire to learn:

ME2: I think it creates curiosity like it's good fun when you sometimes receive classes and then you go down the stairs "wow!" it is going to be so cool as well so I think it creates a bit of curiosity in the same way that maybe hopefully workshops do with programming.

The museum educators reflected on the fact that, within the framework of the program, they did not make the most of the museum's resources. Initially, in their presentation to the teachers and pupils, the educators talked about what constitutes a museum and what it offers, but they reflected later that the objects and collections could have been used much more. The program mostly offered science-centred activities and other types of installations, but not all of the museum's (potential) resources were used. The educators concluded that they could actually interweave stories about objects with the technology-historical aspects in the programming lessons. The institutional framing of the museum, with its collections and exhibitions, was not fully utilized.

\section{Empowerment vs. competence}

The teachers expressed that the socially vulnerable areas in which the program was carried out had a lack of economic, social, and cultural resources. The school could not rely on families when it came to developing digital skills. For example, many parents did not know how to find information online. They did not have computers or iPads at home, although most families had cell phones. Another lack of resources was manifested in that these families did not visit museums, and did not even go into the central part of the city. The teachers, on the other hand, saw the entire city as a social resource, as a way of being part of the entire community. And since the kids were not used to going to museums, they had not developed norms about how to move and behave in a museum. An important aspect of participating in the program was thus not only about programming as such, but also about understanding the institutional framing and developing a broader social competence-empowerment.

T1: So this is sooo important, they look forward to everything like this, they become hyperactive when they know they are going to be on a school trip. We know that their parents do not go out with them like this . . they can talk about this for several days before it is time to go

T2: So just the bus trip is so big and having lunch there is so important, it is so important

T1: And when they come to the entrance, when it's big and bright ... 
Another important part of empowerment was, according to the teachers, language development, and that the museum educators introduced and used domain-specific words related to both museums and programming.

T4: They left the museums with new concepts; sensor, alarm, new words for them. . I remember the educators repeated them several times, but they can also be written somewhere, also as a teacher you could get a glossary before the visit ...

However, not all museum educators were able to adapt their language to this particular social group of pupils. If the children did not understand, they lost interest and commitment. Both educators and teachers commented on the differences between their agendas and how they could allow for better collaboration. Considering the needs of this particular group of pupils, the challenge for the museum educators is to take advantage of the institutional framing of the museum whichcompared to the school—offers other possibilities for empowerment.

\section{Conclusion and discussion}

In this chapter, we have presented some of the challenges and opportunities for teaching and learning in the collaboration between a school and a science and technology museum. Using a design-theoretic perspective, we demonstrated how the museum contributed to the curricular aims of the school by offering an activity which took place not only at the museum but also at the participating school's site (see Phillips et al., 2007). As Griffin (2007) asserted, museum educators and school teachers need a better understanding of each other's pedagogical contexts and strategies in order for the partnership to succeed. By way of developing something in common, the two partners came to understand each other's educational roles better, as well as how their different institutional framings shaped different strategies for developing programming. The experiences from the collaboration could feed into the discussions at the school where the teachers were expected to develop their local educational plan for programming, including both enjoyment and programming skills. The findings illustrate not only how institutional aims and norms frame learning in different ways, but also that there is a space for doing things differently and trying out new patterns for learning. This is despite the fact that the museum often put the purposes of education and enjoyment first, whereas the school was more focused on curricular aims and learning outcomes.

From the museum's perspective, the Touring Science Centre programme was designed to spark an interest in programming, through the choice of materiality and activities. Programming was represented as a playful game, as was the case with the robot obstacle course that could be mastered through collective problem-solving. In contrast to this, the school teachers talked about the need for increased skills in programming. They pointed out that their reasons 
for participating were not just to have fun, but to make sure that the curricular goals were met. Another goal was to develop pupils' self-confidence and their competence to take charge of their own growth for participation in society.

It seems clear that even though the school and the museum each framed programming differently, in terms of either enjoyment or learning, this did not cause any problems in terms of power relations between the two professional groups, museum educators and school teachers. Rather, participating in the museum's programme became a useful first step for the teachers in their work to develop the school's local strategy for programming. In this case, museum educators and school teachers each had well-defined roles, and were both involved in the activities that took place in school and at the museum (cf. Mathewson \& McKeon, 2002; Griffin, 2007). The design of the workshops-with hands-on materials and the guidance of the museum educators-made it easier for the teachers to gain an understanding of what programming could involve.

The specific resources of the museum - both material and human-were considered an important part of understanding and doing programming. However, the museum educators reflected on the fact that, within the framework of the program, they did not really use the museum's collections as much as they could have. A "collection" is often seen as "the" central hub, as a starting point for the museum's activities. In this program, the opposite was true-it was through the practical materials in the workshops that it was possible to frame programming as science and technology during the museum visit. In this way, teachers could benefit from and contribute to the school's curricula, inspired by the informal learning environment at the science centre (see Cox-Petersen et al., 2003; Allen, 2004).

The teachers emphasized that the socially vulnerable areas where the program was carried out had a lack of economic as well as social and cultural resources. They saw great value in being able to visit a museum, but this was something new for both the school and the pupils' families. The participation in the program also contributed to the empowerment of these pupils. Another important aspect of empowerment is the competence to use the Swedish language in a broader as well as in a more domain-specific way than it is used in day-to-day talk among pals. Therefore, it was important that the museum educators introduced and used domain-specific words related to programming, as well as talking about the museum in more general terms that strengthened the empowerment of the pupils, something which complements the work in the formal framing of the school (cf. Bowler et al., 2016; Mesiti et al., 2019; Moore et al., 2020).

However, it could also be noted that, in terms of language learning, there seems to be a lack of deeper dialogue between the museum and the school. The Touring Science Centre programme has been running and evaluated for a number of years, and has also been re-designed and transformed during those years. Nevertheless, the museum's educators did not specifically perceive the language issue as prominent when we discussed their work in this socially 
vulnerable area. In the preparations for the visit to the schools and the museum, the museum educators' focus was primarily on rules and behaviour rather than on creating a dialogue about possible forms of language support. Although the programming instructions were visualized through the use of symbols during the workshops, the teachers stressed that a glossary would have been supportive in relating the domain-specific concepts to the students' everyday lives. The interviews with the teachers highlight how language development could be emphasized in the programme as a design for learning, and in that way contribute to the design and transformation of programming within the formal framing of the school.

\section{Note}

11994.

\section{References}

Allen, S. (2004). Designs for learning: Studying science museum exhibits that do more than entertain. Science Education, 88(1), 17-33.

Bowler, L., \& Champagne, R. (2016). Mindful makers: Question prompts to help guide young peoples' critical technical practices in maker spaces in libraries, museums, and communitybased youth organizations. Library and Information Science Research, 38(2), 117-124.

Cigdemoglu, C., \& Köseoğlu, F. (2019). Improving science teachers' views about scientific inquiry: Reflections from a professional development program aiming to advance science centre-school curricula integration. Science \& Education, 28, 439-469.

Cox-Petersen, A., Marsh, D. D., Kisiel, J., \& Melber, L. M. (2003). An investigation of guided school tours, pupil learning, and science reform: Recommendations at a museum of natural history. Journal of Research in Science Teaching, 40(2), 200-218.

Griffin, J. (2007). Pupils, teachers, and museums: Toward an intertwined learning circle. In J. H. Falk, L. D. Dierking, \& S. Foutz (Eds.), In principle, in practice: Museums as learning institutions. AltaMira Press.

Kjällander, S., Åkerfeldt, A., \& Petersen, P. (2016). Översikt avseende forskning och erfarenheter kring programmering i förskola och grundskola [Overview regarding research and experiences of programming in preschool and primary school]. Skolverket.

Kress, G., \& Selander, S. (2012). Multimodal design, learning and cultures of recognition. The Internet and Higher Education, 15(4), 265-268. https://doi.org/10.1016/j.iheduc.2011. 12.003

Mathewson, D., \& McKeon, P. (2002, December 1-5). Disrupting notions of collaboration: The problematic engagement of museums and schools. Paper presented at the Annual Conference of the Australian Association for Research in Education, Brisbane. www.aare.edu.au/data/ publications/2002/mat02555.pdf. Retrieved 2020-05-20.

Mesiti, A. L., Parkes, A., Paneto, S. C., \& Cahill, C. (2019). Building capacity for computational thinking in youth through informal education. Journal of Museum Education, 44(1), 108121. https://doi.org/10.1080/10598650.2018.1558656

Moore, S., Roche, J., Bell, L., \& Neenan, E. E. (2020). Supporting facilitators of maker activities through reflective practice. Journal of Museum Education, 45(1), 99-107. https://doi.org/ 10.1080/10598650.2019.1710688 
Nouri, J., Zhang, L., Mannila, L., \& Norén, E. (2020). Development of computational thinking, digital competence and 21st century skills when learning programming in K-9. Education Inquiry, 11(1), 1-17. https://doi.org/10.1080/20004508.2019.1627844

Phillips, M., Finkelstein, D., \& Wever-Frerichs, S. (2007). School site to museum floor: How informal science institutions work with schools. International Journal of Science Education, 29(12), 1489-1507. https://doi.org/10.1080/09500690701494084

Swedish National Agency for Education. (2011). Curriculum for the compulsory school, preschool class and the recreation centre, Lgr11 (revised 2018). Skolverket. 